\title{
UNA CLASIFICACIÓN DE LOS ESTABLECIMIENTOS DE OCIO NOCTURNO: EL CASO DE IBIZA (ESPAÑA)
}

\author{
J. R. CARDONA ${ }^{1}$, M. C. AZPELICUETA-CRIADO ${ }^{1 *}$ y M. D. SÁNCHEZ-FERNÁNDEZ ${ }^{2}$ \\ Universitat de les Illes Balears - España \\ Universidad da Coruña - España \\ msanchezf@udc.es*
}

Artículo presentado en marzo/2016 y aceptado en septiembre/2016

DOI: $10.15628 /$ holos.2016.4301

\begin{abstract}
RESUMEN
Ibiza es muy conocida por sus discotecas y fiestas, siendo uno de los referentes mundiales del sector. El objetivo de este trabajo es realizar una primera propuesta de clasificación de los establecimientos con eventos musicales en la isla de Ibiza. La metodología se basa en la consulta de bibliografía, prensa local y páginas web especializadas. La clasificación fue realizada en base a la actividad principal, la relevancia y las características de la oferta de eventos. Por una parte hay las discotecas, que pueden dividirse en macrodiscotecas de relevancia internacional como son Amnesia, Pachá o Space, y discotecas de relevancia eminentemente local y poco conocidas fuera de la isla. Por otra parte, existe una
\end{abstract}

oferta formada por los Beach Clubs, los Lounge Clubs, los Disco Pubs, los Hotel Clubs, los restaurantes espectáculo y los Party Boats. La principal diferencia entre los dos grandes grupos es que las discotecas son establecimientos cuya actividad declarada principal es el ocio nocturno, cobrando entrada, y el segundo grupo son empresas cuya actividad principal es la hostelería pero han adoptado los eventos musicales como elemento diferenciador. Es un importante reto de futuro la regulación de una oferta que engloba a tantos tipos de establecimientos distintos, reduciendo los impactos negativos sobre los residentes sin limitar la actividad empresarial.

PALABRAS CLAVE: Ibiza, Ocio Nocturno, Oferta, Clasificación, Tipos.

\section{A CLASSIFICATION OF NIGHTLIFE ESTABLISHMENTS: THE CASE OF IBIZA (SPAIN)}

\begin{abstract}
Ibiza is well known for its clubs and parties, being one of the world leaders of the sector. The objective of this work is a first proposal for the classification of establishments with musical events on the island of Ibiza. The methodology is based on the consultation of literature, local press and specialized websites. The classification was made based on the core business, the relevance and characteristics of the events supply. On the one hand there are nightclubs, which can be divided into macronightclubs of international importance such as Amnesia, Pacha and Space, and nightclubs eminently local relevance and little known outside the island. Moreover,
\end{abstract}

there is an offer made by the Beach Clubs, the Lounge Clubs, the Disco Pubs, the Hotel Clubs, the show restaurants and the Party Boats. The main difference between the two groups is that the nightclubs are establishments whose main declared activity is nightlife, charging admission, and the second group is companies whose main activity is hospitality but have adopted the musical events as a differentiator. It is a major challenge for the future the regulation of a supply that encompasses many different types of establishments, reducing negative impacts on residents without limiting the business activity.

KEYWORDS: Ibiza, Nightlife, Supply, Classification, Types. 


\section{INTRODUCCIÓN}

El sector del ocio nocturno posee poca bibliografía académica y normalmente hace referencia a las discotecas como contexto en que se estudian diversos aspectos sociales. Este trabajo busca proponer una clasificación de los establecimientos con eventos existentes en la isla de Ibiza. La utilidad de realizar una propuesta de clasificación es clarificar que establecimientos son competidores directos y cuales complementarios; permite reflejar la existencia de oferta más allá de las discotecas y pubs, etc. Esta clasificación es útil tanto para los empresarios como para los investigadores, enfocando sus estudios y acciones hacia un tipo concreto de oferta. Los establecimientos objeto de estudio tienen el ocio nocturno, concretado la celebración de fiestas o eventos musicales, como elemento característico de su oferta. En unos casos los eventos son la actividad principal (discotecas) y en otros casos complementarios y diferenciadores de su actividad principal pero en todos los casos implica disponer del equipo básico para su celebración de forma permanente, principalmente una mesa de mezclas y equipo de sonido para la sala principal. Quedan excluidos de esta clasificación los establecimientos que celebren eventos de forma muy esporádica, alquilando el equipo necesario en cada caso, y los casos en que los eventos no formen parte de la oferta y promoción habitual.

La importancia mundial de la isla en el sector de las discotecas y el ocio nocturno hace posible la generalización de esta clasificación a otros destinos turísticos con este tipo de oferta. Tras una revisión de la literatura, se expone la historia del ocio nocturno en Ibiza y su importancia actual. Cabe indicar que durante muchos años sólo componían esta oferta los bares y las discotecas, pero a finales de los noventa aparecieron los beach clubs y a partir de 2010 el resto de formatos expuestos. En el siguiente apartado se comenta la metodología utilizada en este estudio. Seguidamente se expone la clasificación propuesta $y$, finalmente, se plantean diversas conclusiones sobre la clasificación.

\section{REVISIÓN DE LA BIBLIOGRAFÍA}

La mayor parte de la bibliografía considera las discotecas un mero contexto o escenario para estudios no directamente relacionados con la gestión empresarial o el marketing. Ejemplos de ello son diversos estudios sobre consumo de drogas, alcohol y tabaco (CALAFAT et al., 2011; DARGAN; ALBERT; WOOD, 2010; ELLEDGE et al., 2011; FORSYTH, 2010; JÄRVINEN; RAVN, 2011; JONES et al., 2011; MAK et al., 2010; RIDNER et al., 2011; STANTON et al., 2011; SUMNALL et al., 2010), conductas violentas (ANDERSON; DALY; RAPP, 2009; FORSYTH; LENNOX, 2010; ROWE et al., 2010), relaciones sexuales de riesgo (BOYD, 2010; DAMANI et al., 2009), accidentes o desastres (AGUIRRE et al., 2011; DEAN; MULLIGAN, 2009), problemas de salud diversos (BEACH; WILLIAMS; GILLIVER, 2011; HALIOS et al., 2009; POTIER et al., 2009) o comportamientos sociales (ALLEMAND, 2010; GUÉGUEN, 2009; HENDRIE; MANNION; GODFREY, 2009; MEASHAM; HADFIELD, 2009; MOSS; PARFITT; SKINNER, 2009) en ambientes de ocio nocturno, discotecas y destinos de turismo de discotecas.

Los estudios que toman como protagonista el ocio nocturno, las discotecas y su gestión son muy escasos. Existen algunos estudios puramente descriptivos de la oferta en Taiwan (HUANG, 2011), el sur de Londres (ANDERSSON, 2011), Belgrado (TODOROVIC; BAKIR, 2005), Milwaukee 
(CAMPO; RYAN, 2008), Los Ángeles (HONG; DUFF, 1997) e Ibiza (RAMÓN; AZPELICUETA; SERRA, 2015) pero sin profundizar en clasificaciones sistemáticas, un grupo de estudios sobre servicescape (KUBACKI et al., 2007; SKINNER et al., 2008; SKINNER; MOSS; PARFITT, 2005) y algún estudio sobre la actitudes de los residentes (RAMÓN; ÁLVAREZ, 2016; SERRA; RAMÓN, 2016). Estos trabajos constituyen las únicas publicaciones de interés para estudiosos de la gestión y el turismo y no se han localizado clasificaciones.

Cabe resaltar que los casinos y el juego tienen mucha más bibliografía que las discotecas y el ocio nocturno (ej. BROWN; ROSEMAN; HAM, 2003; COULTER; HERMANS; PARKER, 2013; JANES; COLLISON, 2004; KO; STEWART, 2002; LEE; BACK, 2003, 2006; LEE; KANG; REISINGER, 2010; LEE; KIM; KANG, 2003; LOCKYER, 2012; NICHOLS; GIACOPASSI; STITT, 2002; STITT; GIACOPASSI; NICHOLS, 2003; SUTTON; GRIFFITHS, 2008; VONG, 2004, 2009; VONG; MCCARTNEY, 2005) a pesar de las similitudes entre ambos tipos de oferta, especialmente en lo referente a los impactos sociales.

\section{OCIO NOCTURNO EN IBIZA}

Ibiza es una isla del mediterráneo occidental de $572 \mathrm{~km}^{2}$ de superficie y más de 140.000 habitantes (IBESTAT, 2015), caracterizada por su fuerte dependencia económica del turismo. Cada año recibe cerca de 2,400.000 turistas, mayoritariamente concentrados en los meses de junio a septiembre (AGÈNCIA DE TURISME DE LES ILLES BALEARS, 2015). Los inicios del turismo en Ibiza se encuentran en el primer tercio del siglo XX, pero fue entre la segunda mitad de los años cincuenta y los setenta cuando se produjo el mayor desarrollo turístico. El rápido crecimiento del sector se debió a que permitió abandonar la situación de pobreza anterior. El turismo siguió creciendo rápidamente hasta que se frenó el crecimiento de plazas turísticas a principios de los noventa y se estabilizaron los volúmenes de turistas hacia el año 2000, manteniéndose más o menos estables las cifras turísticas desde entonces (RAMÓN; SERRA, 2014).

Desde sus inicios, Ibiza creció amparada por una imagen de libertad que atrajo a las vanguardias artísticas europeas en un primer momento y, posteriormente, a los beatniks y los hippies. Este ambiente de libertad favoreció que existieran fiestas privadas y locales nocturnos impensables en los años cincuenta, y no sólo en España. Son de esta época los primeros bares precursores de la futura oferta nocturna ibicenca, situados en el puerto de Ibiza y en Sant Antoni. En los sesenta y setenta las fiestas promovidas por la comunidad hippie tomaron una presencia importante y algunas de ellas se han convertido en una tradición que aún perdura. Entre finales de los sesenta y principios de los setenta abrieron las primeras discotecas de la isla. De esa época destaca Pachá (Figura 1), situada en el prado sobre el que hoy se sitúa el Paseo Marítimo. En general, las discotecas de los setenta eran pequeños establecimientos con pocos trabajadores y un equipo técnico adecuado para la época pero modesto. Estos establecimientos crecieron rápidamente en tamaño, tecnología y prestigio, llegando algunos hasta la actualidad.

La imagen de Ibiza sería difícil de explicar sin el auge de las discotecas en los ochenta. Se produjo un incremento del número y las dimensiones de las discotecas ibicencas, espoleado por el auge de los clubs del Reino Unido. En los años ochenta Pacha, Angel's, Playboy, Amnesia y Ku constituían reclamos turísticos de fama mundial. De entre estas discotecas destacaba Ku (hoy Privilege), en Sant Rafel, como referente y símbolo de la oferta nocturna de la isla (RAMÓN, 2001). A principios de los noventa se produjo una reducción de este auge, en parte por los cambios de 
tendencia que se produjeron en el Reino Unido y en parte por la crisis turística y la nueva normativa. En los años noventa se intento corregir la imagen de destino turístico de desenfreno y fiesta para no ahuyentar a otros tipos de turismo. A pesar de ello, en los noventa se formó un grupo de locales que son imagen de la isla (Amnesia, Edén, Es Paradís, Pacha, Privilege y Space). A partir de los noventa se aplicaron limitaciones a las discotecas para evitar las molestias que generaban a los residentes y se popularizaron nuevas fórmulas de establecimientos de ocio nocturno, como son los Beach Clubs y los Hotel Clubs (DIARIO DE IBIZA, 21 de agosto de 2013), que esquivan las restricciones aplicadas a las discotecas.

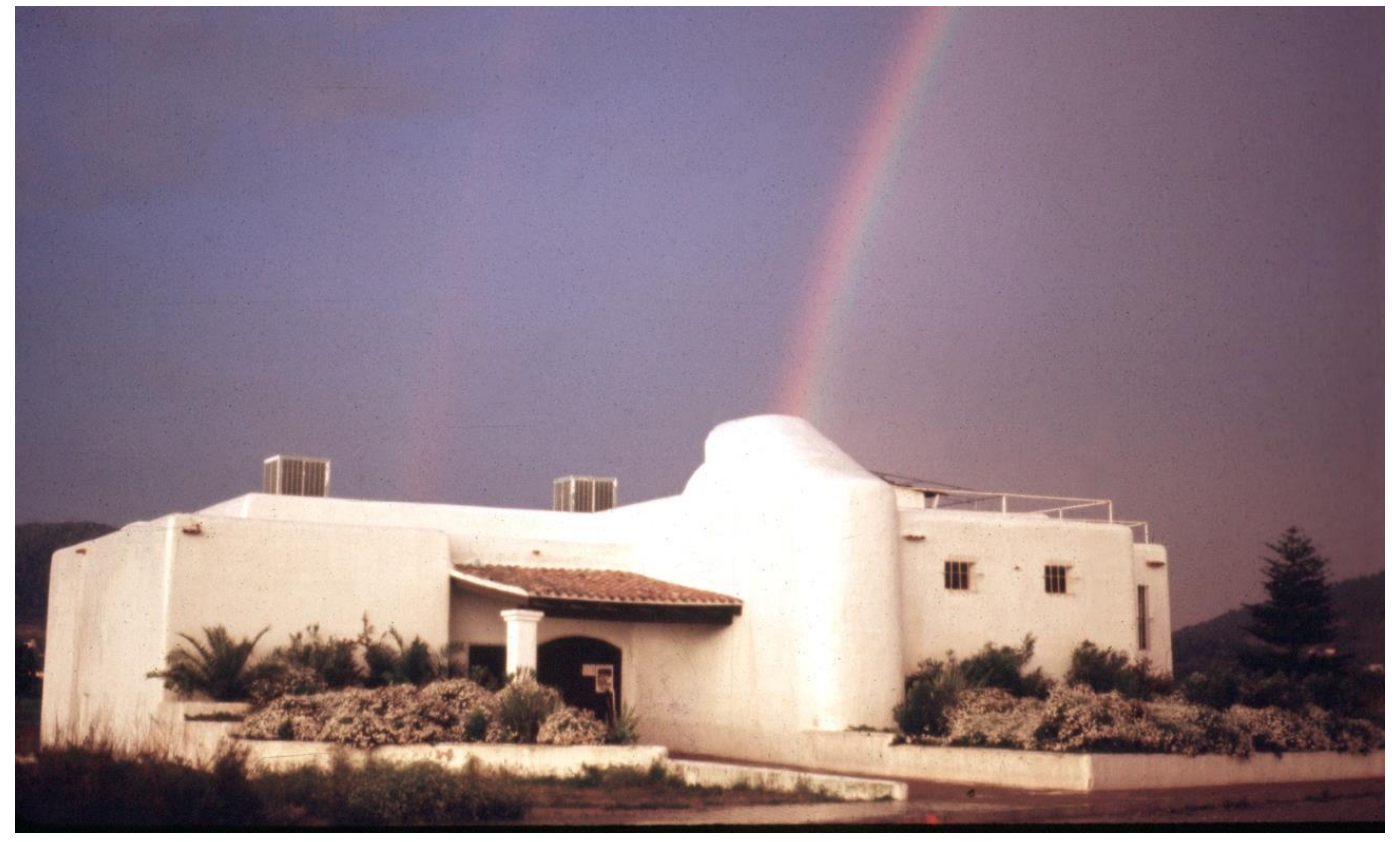

Figura 1: Discoteca Pachá en los setenta (GRUPO PACHA).

Vinculado a la fama mundial de Ibiza, apareció el fenómeno de los clubbers. Traídos fundamentalmente desde Gran Bretaña por grupos como Ministry of Sound, Cream, Manumisión, etc., miles de jóvenes turistas comenzaron a venir a la isla exclusivamente atraídos por las fiestas de las grandes discotecas. Vicente de Oteyza indicaba que nada tenía que ver el clubber con el hooligan.

[Los clubbers] proceden de las clases media o media-alta, exhiben glamur en su vestimenta y en su estilo y son incondicionales adoradores de sus ídolos del techno, el house, el jungla, el trance o el garage. Más que ligar en las discotecas buscan trabar una simple amistad para disfrutar de la música y del baile trepidante (DIARIO DE IBIZA, 8 de octubre de 2000).

La importancia mundial de las discotecas de Ibiza se puede observar en diversas referencias del sector. Dentro de los Annual International Dance Music Awards, que son parte de la Miami Winter Music Conference, se crearon en 2005 las categorías Best Global Club y Best US Club. En la categoría Best Global Club (Tabla 1) han sido nominadas siempre Amnesia y Space, y, de once ediciones, han ganado en diez ocasiones discotecas de Ibiza (cinco Space, cuatro Amnesia y una Ushuaïa). La revista DJMag, referente del sector, publica anualmente rankings de las cien mejores discotecas. De las 20 primeras de 2015 (Tabla 2), 5 son de Ibiza (Space, Pacha, Amnesia, Ushuaïa y DC10). Dos discotecas más se encuentran en el listado: Sankeys y Privilege.

Tabla 1: Categoría Best Global Club. 


\begin{tabular}{|c|c|c|c|c|c|c|c|c|c|c|c|}
\hline CLUB & 05 & 06 & 07 & 08 & 09 & 10 & 11 & 12 & 13 & 14 & 15 \\
\hline Amnesia (Ibiza) & $\mathrm{N}$ & $\mathrm{N}$ & $\mathbf{w}$ & $\mathbf{w}$ & $\mathbf{w}$ & $\mathrm{N}$ & $\mathbf{w}$ & $\mathrm{N}$ & $\mathrm{N}$ & $\mathrm{N}$ & $\mathrm{N}$ \\
\hline $\begin{array}{l}\text { Berghain (Berlín) } \\
\text { CocoonClub (Frankfurt) }\end{array}$ & & & & & $\mathrm{N}$ & & $\mathrm{N}$ & & $\mathrm{N}$ & $\mathrm{N}$ & $\mathrm{N}$ \\
\hline DC-10 (Ibiza) & & & & & & & & & & $\mathrm{N}$ & \\
\hline $\begin{array}{l}\text { Fabric (Londres) } \\
\text { Godskitchen (Londres) } \\
\text { Green Valley (Camboriú) } \\
\text { Ministry of Sound (Londres) }\end{array}$ & $\begin{array}{l}\mathrm{N} \\
\mathrm{N}\end{array}$ & $\mathrm{N}$ & $\mathrm{N}$ & & $\mathrm{N}$ & $\begin{array}{l}\mathrm{N} \\
\mathrm{N} \\
\mathrm{W}\end{array}$ & $\mathrm{N}$ & $\mathrm{N}$ & $\mathrm{N}$ & $\mathrm{N}$ & $\mathrm{N}$ \\
\hline Pachá (Ibiza) & $\mathrm{N}$ & $\mathrm{N}$ & $\mathrm{N}$ & $\mathrm{N}$ & $\mathrm{N}$ & $\mathrm{N}$ & $\mathrm{N}$ & $\mathrm{N}$ & $\mathrm{N}$ & & $\mathrm{N}$ \\
\hline Pachá (Londres) & & & $\mathrm{N}$ & & & & & & & & \\
\hline $\begin{array}{l}\text { Privilege (Ibiza) } \\
\text { Space (Ibiza) }\end{array}$ & $\mathbf{w}$ & $\mathbf{w}$ & $\mathrm{N}$ & $\mathrm{N}$ & $\mathrm{N}$ & $\mathrm{N}$ & $\begin{array}{l}\mathrm{N} \\
\mathrm{N}\end{array}$ & $\mathbf{w}$ & $\begin{array}{l}\mathrm{N} \\
\mathrm{W}\end{array}$ & $\begin{array}{l}\mathrm{N} \\
\mathbf{W}\end{array}$ & $\mathrm{N}$ \\
\hline $\begin{array}{l}\text { Stereo (Montreal) } \\
\text { The Guvernment (Toronto) }\end{array}$ & & & & $\begin{array}{l}\mathrm{N} \\
\mathrm{N}\end{array}$ & $\mathrm{N}$ & $\mathrm{N}$ & $\mathrm{N}$ & $\mathrm{N}$ & $\mathrm{N}$ & & \\
\hline Ushuaïa (Ibiza) & & & & & & & & & & & w \\
\hline Zouk (Singapur) & & & & & & & & $\mathrm{N}$ & $\mathrm{N}$ & & \\
\hline
\end{tabular}

N: Nominada; W: Ganadora.

Fuente: Winter Music Conference.

A pesar de la importancia mundial de las discotecas de lbiza, los estudios académicos existentes poseen el mismo enfoque que en el resto del mundo, siendo un mero contexto para estudios sobre consumo de drogas (BELLIS et al., 2003, 2009; HUGHES et al., 2009), conductas violentas (Hughes et al., 2008) y relaciones sexuales de riesgo (BELLIS; HUGHES, 2004; DOWNING et al., 2011; HUGHES; BELLIS, 2006), salvo en algunos trabajos recientes (ej. RAMÓN; AZPELICUETA; SERRA, 2015; SERRA; RAMÓN, 2016).

Tabla 2: Top 100 Clubs.

\begin{tabular}{|c|c|c|c|c|c|c|}
\hline 2013 & 2014 & 2015 & Club & CIUDAD & País & AFORO \\
\hline 1 & 2 & 1 & Green Valley & Camboriú & Brasil & 8.000 \\
\hline \multirow[t]{2}{*}{2} & 1 & 2 & Space & Ibiza & España & 3.150 \\
\hline & 10 & 3 & Hakkasan & Las Vegas & Estados Unidos & 3.024 \\
\hline 3 & 3 & 4 & Pacha & Ibiza & España & 3.000 \\
\hline 10 & 6 & 5 & Amnesia & Ibiza & España & 5.000 \\
\hline 12 & 9 & 6 & Octagon & Seúl & Corea & 2.000 \\
\hline 5 & 7 & 7 & Zouk & Singapur & Singapur & 4.000 \\
\hline 6 & 5 & 8 & $\mathrm{BCM}$ & Mallorca & España & 3.000 \\
\hline 28 & 11 & 9 & Ushuaïa & Ibiza & España & 4.500 \\
\hline 8 & 8 & 10 & Sirena & Sào Sebastiào & Brasil & 4.000 \\
\hline 7 & 12 & 11 & Ministry of Sound & Londres & Reino Unido & 1.500 \\
\hline 19 & 26 & 12 & Warehourse Project & Manchester & Reino Unido & 2.000 \\
\hline 18 & 14 & 13 & Berghain/Panorama Bar & Berlín & Alemania & 1.500 \\
\hline 14 & 16 & 14 & DC10 & Ibiza & España & 1.500 \\
\hline 4 & 4 & 15 & Fabric & Londres & Reino Unido & 1.600 \\
\hline 27 & 18 & 16 & Cocorico & Rímini & Italia & 6.000 \\
\hline 33 & 20 & 17 & Paradise Club & Mykonos & Grecia & 5.000 \\
\hline 38 & 19 & 18 & Echostage & Washington DC & Estados Unidos & 3.000 \\
\hline 23 & 21 & 19 & Anzu & Sao Paulo & Brasil & 3.000 \\
\hline \multirow[t]{2}{*}{25} & 23 & 20 & Papaya & Pag & Croacia & 5.000 \\
\hline & & 21 & Life & Las Vegas & Estados Unidos & 1.800 \\
\hline 48 & 32 & 22 & Bootshaus & Colonia & Alemania & 1.500 \\
\hline 13 & 24 & 23 & Cavo Paradiso & Mykonos & Grecia & 2.800 \\
\hline \multirow[t]{2}{*}{31} & 29 & 24 & Motion & Bristol & Reino Unido & 1.450 \\
\hline & & 25 & Drai's & Las Vegas & Estados Unidos & 2.500 \\
\hline
\end{tabular}




\begin{tabular}{|c|c|c|c|c|c|c|}
\hline 16 & 17 & 26 & Warung & Camboriú & Brasil & 2.500 \\
\hline 11 & 15 & 27 & Marquee & Las Vegas & Estados Unidos & 3.000 \\
\hline 20 & 25 & 28 & Yalta & Sofía & Bulgaria & 1.000 \\
\hline 15 & 13 & 29 & Guaba Beach Bar & Limassol & Chipre & 2.500 \\
\hline 35 & 27 & 30 & Trouw & Ámsterdam & Holanda & 1.100 \\
\hline 80 & 28 & 31 & Sankeys & Ibiza & España & 1.500 \\
\hline 34 & 37 & 32 & Surrender/Encore & Las Vegas & Estados Unidos & 3.000 \\
\hline \multirow[t]{2}{*}{53} & 30 & 33 & Air & Ámsterdam & Holanda & 1.300 \\
\hline & 39 & 34 & Sky Room & Ribeirao Preto & Brasil & 700 \\
\hline 56 & 44 & 35 & Digital & Newcastle & Reino Unido & 2.200 \\
\hline \multirow[t]{3}{*}{88} & 93 & 36 & Arma 17 & Moscu & Rusia & 1.500 \\
\hline & & 37 & Noa Beach Club & Pag & Croacia & 4.000 \\
\hline & 52 & 38 & Zouk & Kuala Lumpur & Malaysia & 2.000 \\
\hline 29 & 46 & 39 & Duel: Beat & Nápoles & Italia & 1.500 \\
\hline \multirow[t]{2}{*}{60} & 59 & 40 & Exchange & Los Ángeles & Estados Unidos & 1.500 \\
\hline & 47 & 41 & Matahari & Indaial & Brasil & 5.000 \\
\hline \multirow[t]{3}{*}{24} & & 42 & Elrow & Barcelona & España & 2.500 \\
\hline & & 43 & Baum & Bogotá & Colombia & 800 \\
\hline & & 44 & Altromondo Studios & Rímini & Italia & 2.400 \\
\hline 49 & 40 & 45 & Avalon & Los Ángeles & Estados Unidos & 2.000 \\
\hline \multirow[t]{2}{*}{46} & 50 & 46 & Space & Miami & Estados Unidos & 2.500 \\
\hline & & 47 & El Fortin & Porto Belo & Brasil & 7.500 \\
\hline 64 & 49 & 48 & Womb & Tokio & Japón & 1.000 \\
\hline 54 & 57 & 49 & Guendalina & Lecce & Italia & 4.000 \\
\hline 71 & 56 & 50 & Warehourse & Leeds & Reino Unido & 750 \\
\hline \multirow[t]{3}{*}{9} & 22 & 51 & Fabrik & Madrid & España & 4.500 \\
\hline & 53 & 52 & New City Gas & Montreal & Canadá & 2.500 \\
\hline & 82 & 53 & Aquarius & Pag & Croacia & 3.000 \\
\hline \multirow[t]{2}{*}{37} & 48 & 54 & Studio 80 & Ámsterdam & Holanda & 350 \\
\hline & 60 & 55 & Light Nightclub & Las Vegas & Estados Unidos & 2.000 \\
\hline 87 & 77 & 56 & Cacao Beach & Sunny Beach & Bulgaria & 1.500 \\
\hline 32 & 42 & 57 & D-Edge & Sao Paulo & Brasil & 900 \\
\hline \multirow[t]{2}{*}{47} & 66 & 58 & Mansion & Miami & Estados Unidos & 2.500 \\
\hline & & 59 & Output & New York & Estados Unidos & 1.000 \\
\hline 17 & 33 & 60 & Privilege & Ibiza & España & 10.000 \\
\hline \multirow[t]{2}{*}{26} & 31 & 61 & Pacha & New York & Estados Unidos & 2.500 \\
\hline & 69 & 62 & Control & Leed & Reino Unido & 3.100 \\
\hline \multirow[t]{2}{*}{66} & 65 & 63 & Stealth & Nottingham & Reino Unido & 660 \\
\hline & & 64 & Versuz & Hasselt & Bélgica & 3.000 \\
\hline 78 & 88 & 65 & Rex Club & Paris & France & 700 \\
\hline 79 & 81 & 66 & Cielo & New York & Estados Unidos & 350 \\
\hline 42 & 45 & 67 & Sub Club & Glasgow & Reino Unido & 500 \\
\hline 63 & 51 & 68 & Watergate & Berlín & Alemania & 600 \\
\hline \multirow[t]{2}{*}{22} & 38 & 69 & Guvernment & Toronto & Canadá & 5.000 \\
\hline & 99 & 70 & Egg LDN & Londres & Reino Unido & 900 \\
\hline \multirow[t]{2}{*}{57} & & 71 & Sankeys & Manchester & Reino Unido & 1.100 \\
\hline & & 72 & Fuse & Ho Chi Minh & Vietnam & 500 \\
\hline \multirow[t]{4}{*}{98} & 76 & 73 & Mint Club & Leeds & Reino Unido & 550 \\
\hline & & 74 & Lost Beach Club & Montanita & Ecuador & 4.000 \\
\hline & & 75 & Valkyrie & Manila & Filipinas & 2.000 \\
\hline & & 76 & Danghai & Curitiba & Brasil & 826 \\
\hline 76 & & 77 & La Huaka & Lima & Perú & 1.000 \\
\hline 55 & 72 & 78 & Foundation & Seattle & Estados Unidos & 550 \\
\hline 62 & 73 & 79 & Beta & Waterloo & Canadá & 640 \\
\hline \multirow[t]{3}{*}{92} & 86 & 80 & Corsica Studios & Londres & Reino Unido & 450 \\
\hline & & 81 & Concrete & Paris & France & 1.200 \\
\hline & 97 & 82 & Xoyo & Londres & Reino Unido & 850 \\
\hline
\end{tabular}




\begin{tabular}{c|l|l|l|l|l|r}
65 & 74 & 83 & Robert Johnson & Frankfurt & Alemania & 250 \\
44 & 41 & 84 & Castle Club & Ayia Napa & Chipre & 3.000 \\
41 & 36 & 85 & Space & Sharm El Sheik & Egipto & 5.000 \\
& & 86 & Revelin & Dubrovnik & Croacia & 2.000 \\
85 & 92 & 87 & Tresor & Berlín & Alemania & 1.500 \\
& & 88 & E1leven & Miami & Estados Unidos & 1.000 \\
& & 89 & Teatro Amador & Panamá & Panamá & 400 \\
90 & 80 & 90 & The Arches & Glasgow & Reino Unido & 2.000 \\
& 95 & 91 & Kitty Su & Delhi & India & 800 \\
40 & 58 & 92 & The Mid & Chicago & Estados Unidos & 3.000 \\
& & 93 & Lux & Lisboa & Portugal & 1.500 \\
70 & 62 & 94 & Spartacus Club & Cabriès & France & 1.200 \\
& & 96 & Velvet & Miami & Estados Unidos & 1.500 \\
& & 97 & Loft Metropolis & Asunción & Paraguay & 3.000 \\
& & 98 & Myst & Paris & France & 1.400 \\
93 & 64 & 99 & Tenax & Shanghái & China & 1.200 \\
& 90 & 100 & The Rainbow Venues & Blorence & Italia & 1.500 \\
\hline
\end{tabular}

Fuente: DjMag.

\section{METODOLOGÍA DEL ESTUDIO}

La clasificación de los establecimientos ha sido realizada teniendo en cuenta: el formato legal en el que estén dados de alta (discoteca, bar, restaurante, hotel, charters náuticos, etc.); la relevancia internacional actual o potencial del establecimiento en base al listado de DJMag (Top 100 Clubs) y a los International Dance Music Awards de la Winter Music Conference (categoría Best Global Club); las diferencias en la oferta (precios muy superiores, puesta de sol como atractivo, relevancia de las fiestas celebradas, etc.) y el mercado objetivo (turistas con alto poder adquisitivo, homosexuales, personas de mediana edad, etc.). Las discotecas tienen como oferta principal las fiestas y los eventos musicales, mientras que el resto de formatos tienen otra actividad como principal, siendo los eventos un elemento diferenciador. La presencia habitual de un establecimiento entre los candidatos de los IDMA o entre los 20 primeros del ranking de DJMag se considera máxima relevancia y la presencia esporádica en ambos listados se considera relevancia moderada. Se consideran precios muy superiores cuando duplican los precios de servicios equivalentes en establecimientos similares. La información para realizar esta clasificación se ha obtenido de la consulta de la prensa local, la bibliografía local y las páginas especializadas, además de la visita de algunos establecimientos. Ello ha permitido crear un perfil de los distintos tipos de establecimientos del sector, indicando los elementos más relevantes de cada tipo de oferta.

\section{CLASIFICACIÓN DE LA OFERTA DE OCIO NOCTURNO DE IBIZA}

La innovación ha permitido el liderazgo de la isla en un sector muy complejo y ha llevado a que muchas nuevas ofertas de ocio nocturno tengan sus orígenes o alguno de sus primeros ejemplos en Ibiza. Además, los establecimientos de Ibiza tienen gran relevancia y prestigio tanto entre los profesionales del sector (Tabla 1) como entre los aficionados a la música electrónica (Tabla 2). 

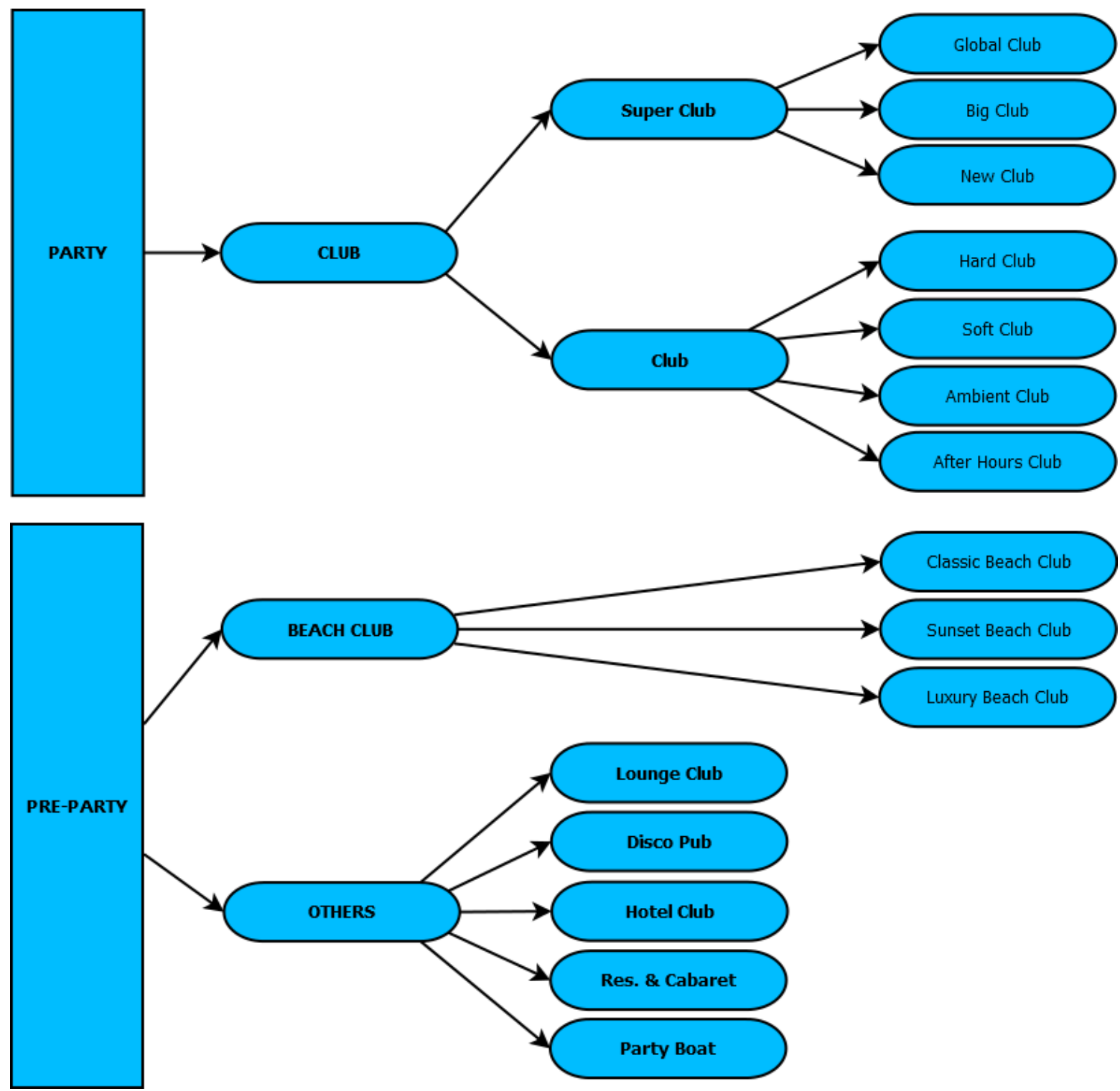

Figura 2: Propuesta de clasificación de los establecimientos.

Los establecimientos de ocio nocturno pueden clasificarse según las características de su oferta en distintos niveles de desagregación (Figura 2). En general, los establecimientos de ocio nocturno pueden clasificarse en dos grandes grupos según las horas principales de su actividad: hasta medianoche (pre-party), y después de medianoche (party):

1. Establecimientos de ocio nocturno principales (party): estos establecimientos se caracterizan porque su momento álgido del día es tras la media noche y son el elemento central de una noche de ocio nocturno. Son básicamente discotecas que están dadas de alta como tales y se les aplica la normativa correspondiente en aforo, seguridad y fiscalidad.

1.1. Discoteca ( $C l u b)$ : la discoteca, club o nightclub, es el establecimiento principal de la oferta nocturna y puede ser de dos tipos, según su relevancia internacional.

1.1.1. Macrodiscotecas de prestigio internacional (Super Club): son establecimientos de gran aforo en el caso de destinos turísticos vacacionales como Ibiza (de 1.500 a 10.000 personas) y que están o aspiran a su presencia en las listas mencionadas en las Tablas 1 y 2 . Las macrodiscotecas estructuran su oferta en un 
calendario de fiestas organizadas por promotores internacionales como productos independientes. Se puede aumentar el desglose dividiéndolas en tres subgrupos:

- Global Club: son las más grandes y veteranas (más de 25 años de historia en todos los casos), y están en al Top10 mundial: Amnesia, Pacha, Space y Privilege (Figura 3).

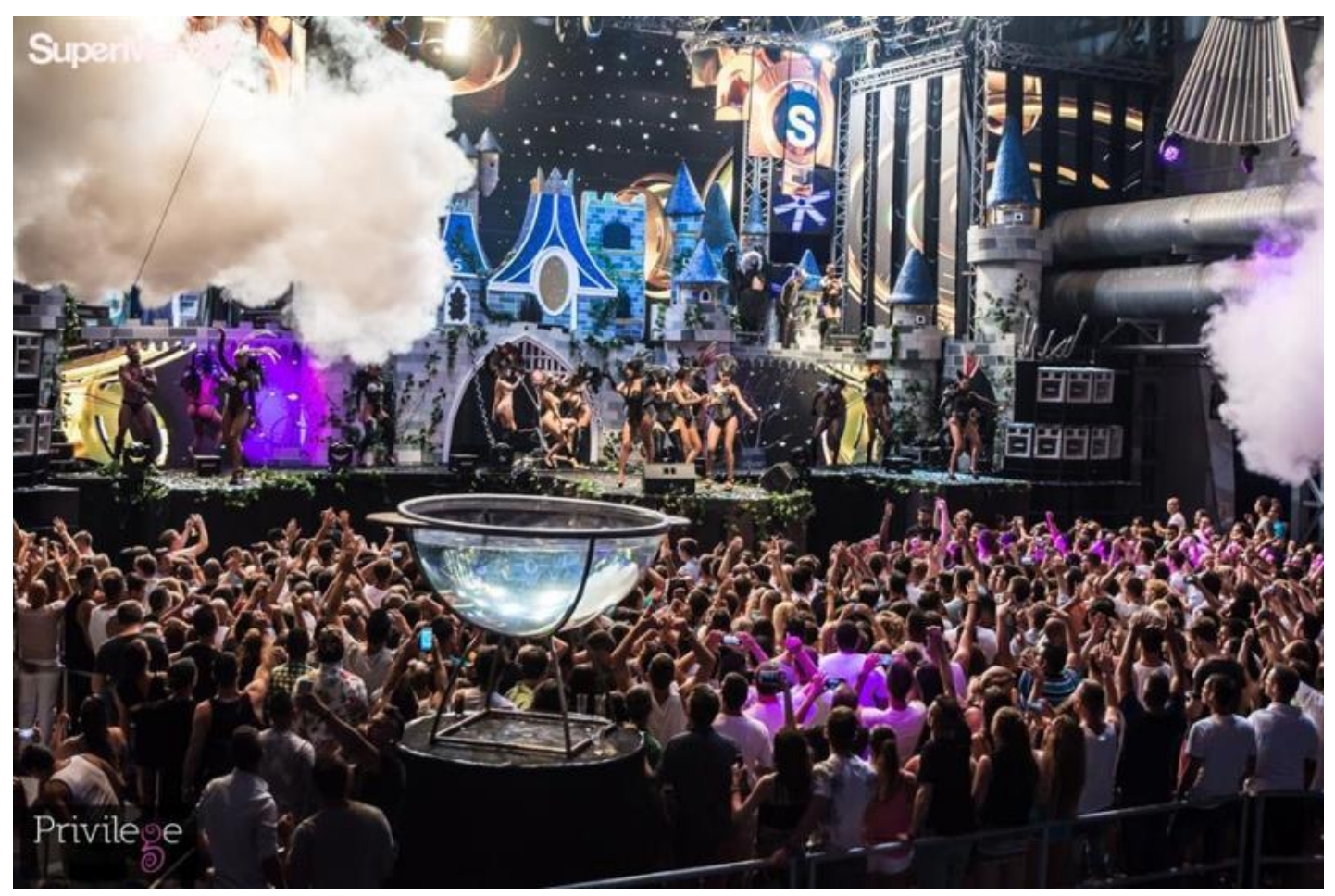

Figura 3: Discoteca Privilege (PRIVILEGE).

- $\quad$ Big Club: son grandes y veteranas, pero sólo aspiran al Top100 mundial. En este grupo estarían Edén y Es Paradís.

- New Club: son de reciente creación y aspirantes a Global Club, ocupando locales que han sido usados para este fin en anteriores ocasiones. En unos casos tienen éxito, como Sankeys Ibiza, pero en otros casos sufren problemas en la gestión y promoción, como Booom! (antes Angel's, Penelope, Heaven, etc.) o MOMA (antes Garbi, Martina, Essence, etc.). Sólo el tiempo dirá si se convertirán en Global Club, Big Club o desaparecerán.

1.1.2. Discotecas convencionales (Club): son discotecas pequeñas, de relevancia eminentemente local, poco conocidas fuera de la isla y no aspiran a los listados internacionales de referencia. En realidad su oferta no se aleja de la que ofrecen establecimientos de núcleos de población sin el prestigio de Ibiza y no tienen capacidad para atraer turistas. Pueden subdividirse en diversos tipos:

- Hard Club: Son pequeños locales con cierta veteranía en el sector y una oferta razonablemente buena (música en vivo o dj's de renombre internacional), siendo el escalafón inmediatamente inferior a las macrodiscotecas. Son ejemplos de ellas Blu, Underground y Zoo Project. 
- $\quad$ Soft Club: Son pequeños locales sin elementos destacables y una oferta de bajo nivel para una destinación como Ibiza (normalmente ausencia de música en directo o dj's desconocidos). Hay muchos ejemplos, principalmente en el West End de Sant Antoni: Casanova, Hogan's, Hot, Hush, Koppas, La Noche, People, Prestige, Rehab, Simple, etc.

- Ambient Club: En la calle de la Virgen del barrio de Sa Peña de Ibiza y en el rabal de Dalt Vila hay la zona de ambiente gay y destacan pequeños locales de gran antigüedad enfocados a este público: Angelo, Dôme, Lola's, S'Ámfora, etc.

- $\quad$ After Hours Club: Aunque en la actualidad se encuentra limitada esta oferta por la normativa municipal, la oferta after hours (fiestas celebradas tras el cierre del resto de establecimientos) tiene presencia en algunos locales desde hace décadas. El caso más emblemático es DC 10 (Figura 4) y esta oferta le ha llevado a sufrir frecuentes cierres temporales por incumplimiento de la normativa. Durante muchos años Space combino la oferta normal y la after hours, aunque la normativa le obligó a abandonar la oferta after.

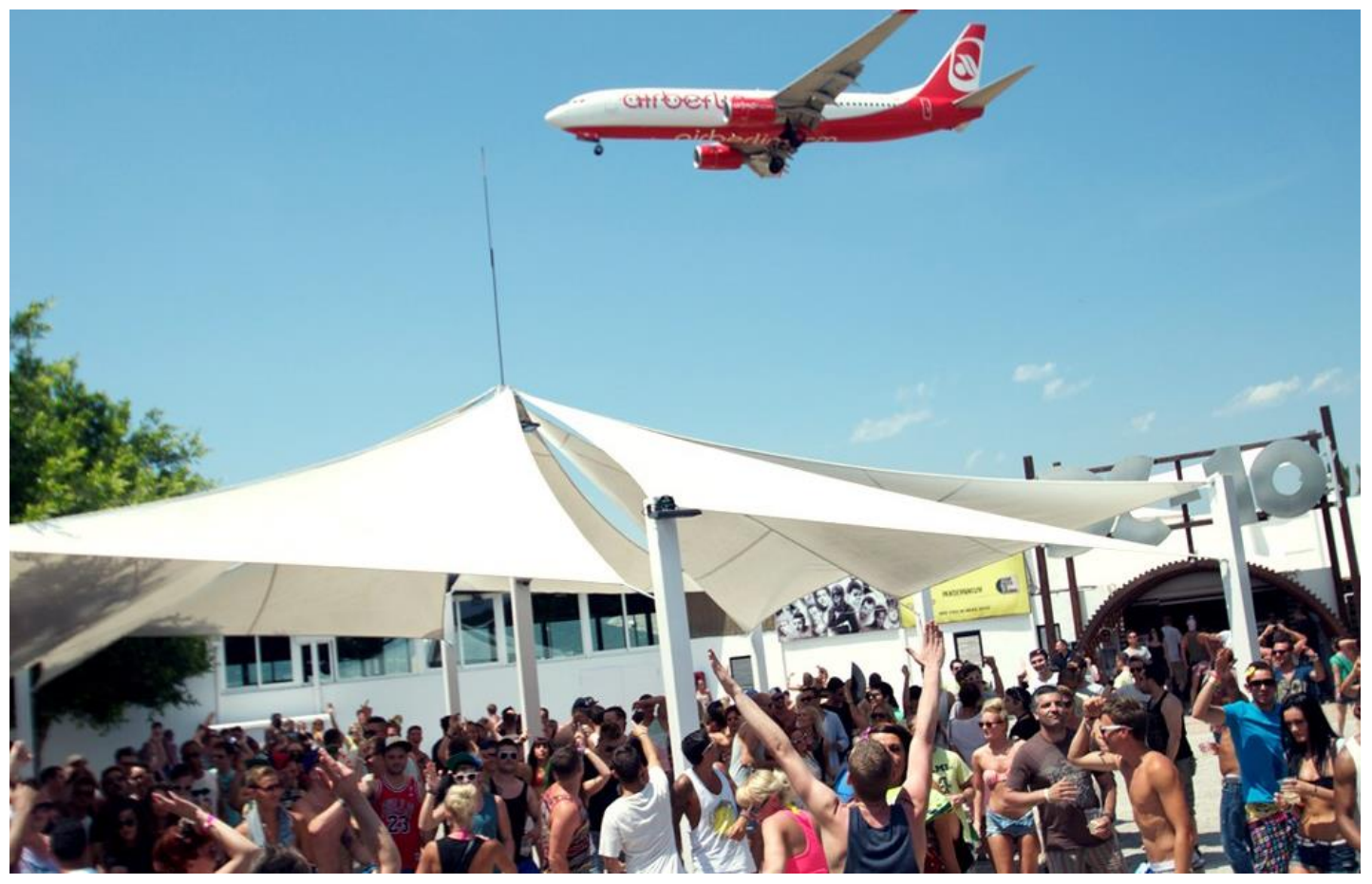

Figura 4: Discoteca DC 10 (GUIDA IBIZA).

2. Establecimientos de ocio nocturno complementarios (Pre-Party): Su momento álgido es antes de la media noche y suelen preceder a las fiestas de las discotecas. No están dados de alta como discotecas, sino como bares, restaurantes, cafeterías etc. y se regulan por la normativa del sector de la hostelería y el turismo.

2.1. Locales de libre acceso situados en las playas (Beach Club): Los Beach Club son una evolución de los establecimientos de comida y bebida situados a pie de playa, y ofrecen música junto a un servicio y ambiente mucho más sofisticado que los establecimientos de playa tradicionales. También tienen precios más elevados que los establecimientos tradicionales. Aunque los primeros de la isla aparecieron en los ochenta, es a partir del 2000 cuando alcanzan gran relevancia internacional y aumentan en número, casi erradicando los 
establecimientos tradicionales en algunas playas. Dentro de los beach club de Ibiza hay tres enfoques principales:

- $\quad$ Classic Beach Club: es el enfoque más tradicional y básico, ofreciendo música electrónica y cócteles en la playa. Los ejemplos más conocidos son Bora Bora (Figura 5), Nassau, Sands, Sirocco y La Plage.

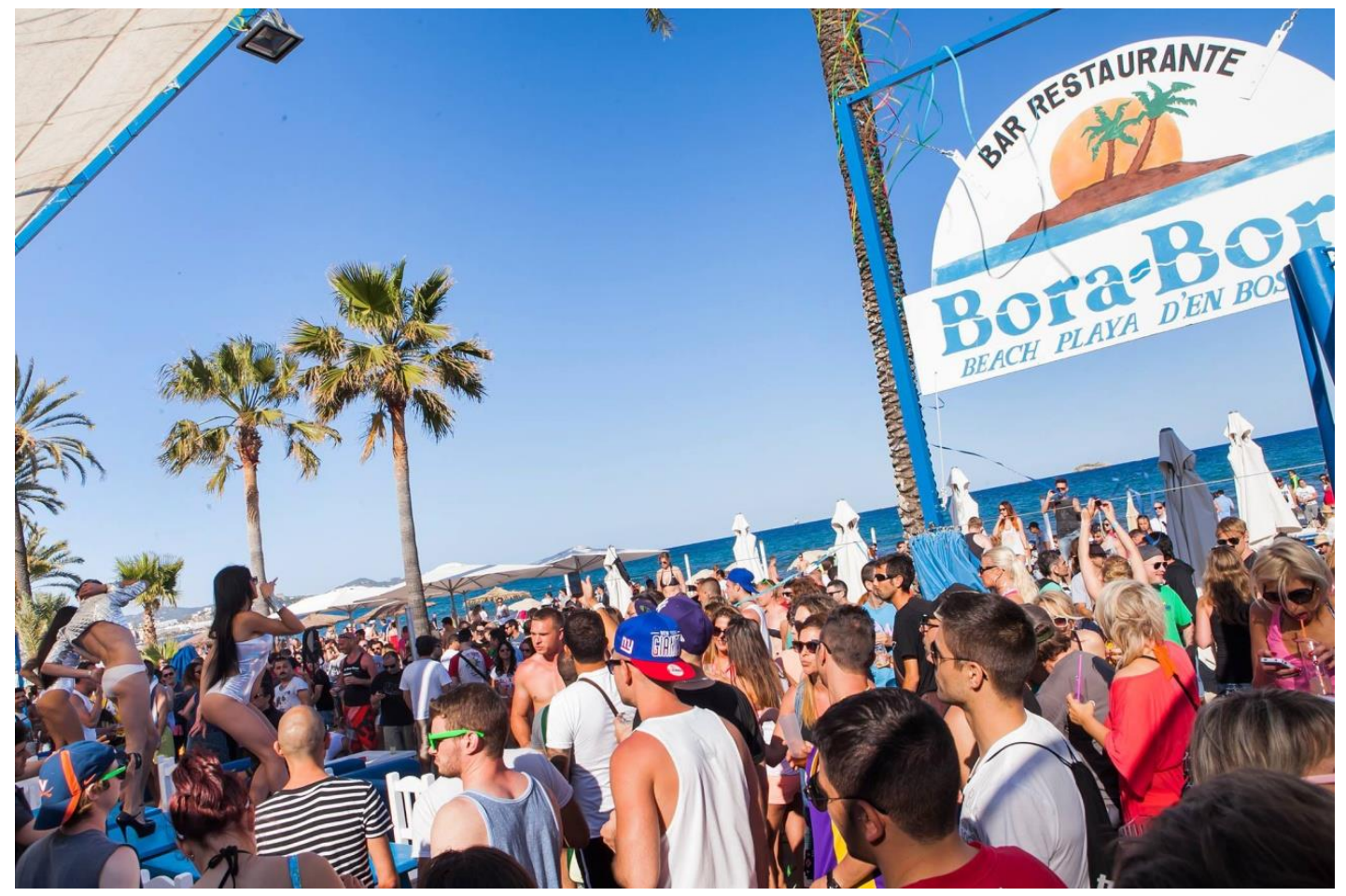

Figura 5: Beach Club Bora Bora, Playa d'en Bossa (BORA BORA).

- Luxury Beach Club: respecto al enfoque clásico, éste implica más lujo y precios más altos (el doble o más). Destacan dentro de este enfoque Blue Marlin y Ocean Beach.

- $\quad$ Sunset Beach Club: al enfoque clásico suman que su principal atractivo es la contemplación de la puesta de sol desde sus mesas. Se sitúan en la parte de poniente de la isla, principalmente la bahía de Sant Antoni, y aunque hay muchos establecimientos conocidos por esta oferta (Café Mambo, Golden Buddha, Kanya, Kumharas, Savannah, Sunsea Bar, The Orange Corner, etc.) el principal es Café del Mar (Figura 6), al ser el promotor y decano de esta oferta comercial que recuerda las costumbres de los hippies inspiradas en cultos solares primitivos. 


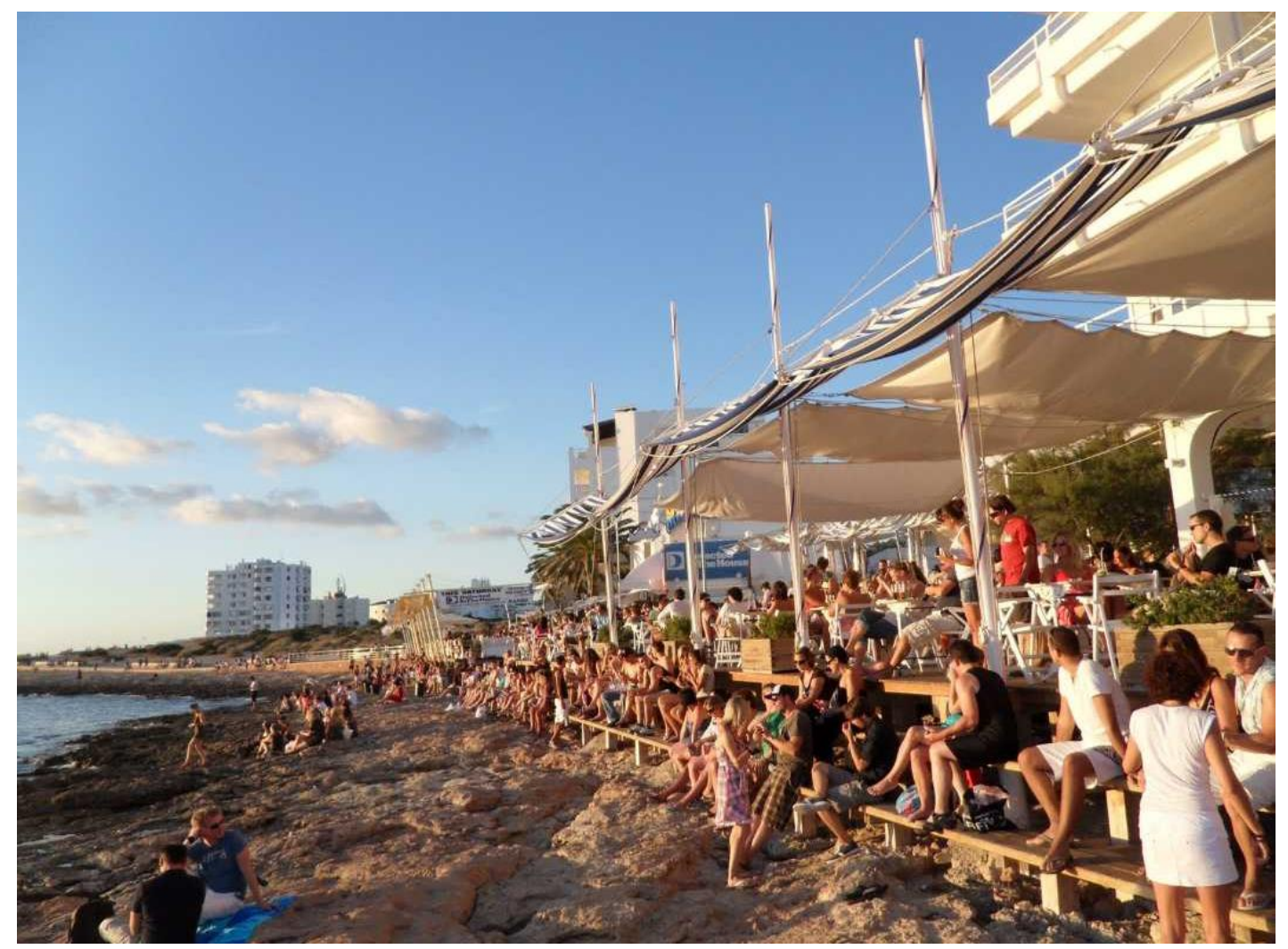

Figura 6: Beach Club Café del Mar, Sant Antoni (CAFÉ DEL MAR).

2.2. Otra oferta musical y de ocio nocturno (Others): La oferta de discotecas y beach clubs se complementa con otros establecimientos.

2.2.1. Lounge Club: los Lounge Club son restaurantes y bares que tienen música chill-out y un ambiente más o menos de inspiración oriental, en cierto modo herederos del espíritu hippie de los sesenta y setenta. Son ejemplos de esta oferta Bambuddha Grove, Km. 5, L'Elephant, Las Dalias, El Ayoun y Villa Mercedes. Su clientela es de mayor edad que en el resto de casos y busca pasar la noche de forma relajada, cenando, bebiendo y charlando con amistades.

2.2.2. Disco Pub: los Disco Pubs son bares de copas con música electrónica y dj's. Son el resultado de la tendencia a incorporar en todo tipo de establecimientos este tipo de música y tiene ejemplos destacables como Angelo's, Clive's, Geminis, Grial, Keeper, Kube, La Biela, Mambo, Match Bar y Savoy.

2.2.3. Hotel Club: los Hotel Clubs son hoteles que se han especializado en organizar grandes eventos de música (electrónica en el Ushuaïa, rock en el Hard Rock Hotel o Rock e indie británico en el lbiza Rocks) en sus establecimientos, generalmente en la zona de la piscina. Es un formato de creación reciente, siendo los primeros de la isla el Ibiza Rocks en 2008 y el Ushuaïa en 2011. En la actualidad existen el Ibiza Rocks Hotel, Ushuaïa Ibiza Beach Hotel (Figura 7), Hard Rock Hotel Ibiza y Destino Ibiza Pacha Hotel \& Resort. Palladium Hotel Group está expandiendo este formato fuera de la isla con un Hard Rock Hotel en Tenerife (España) y un Ushuaïa en Cancún (México). 


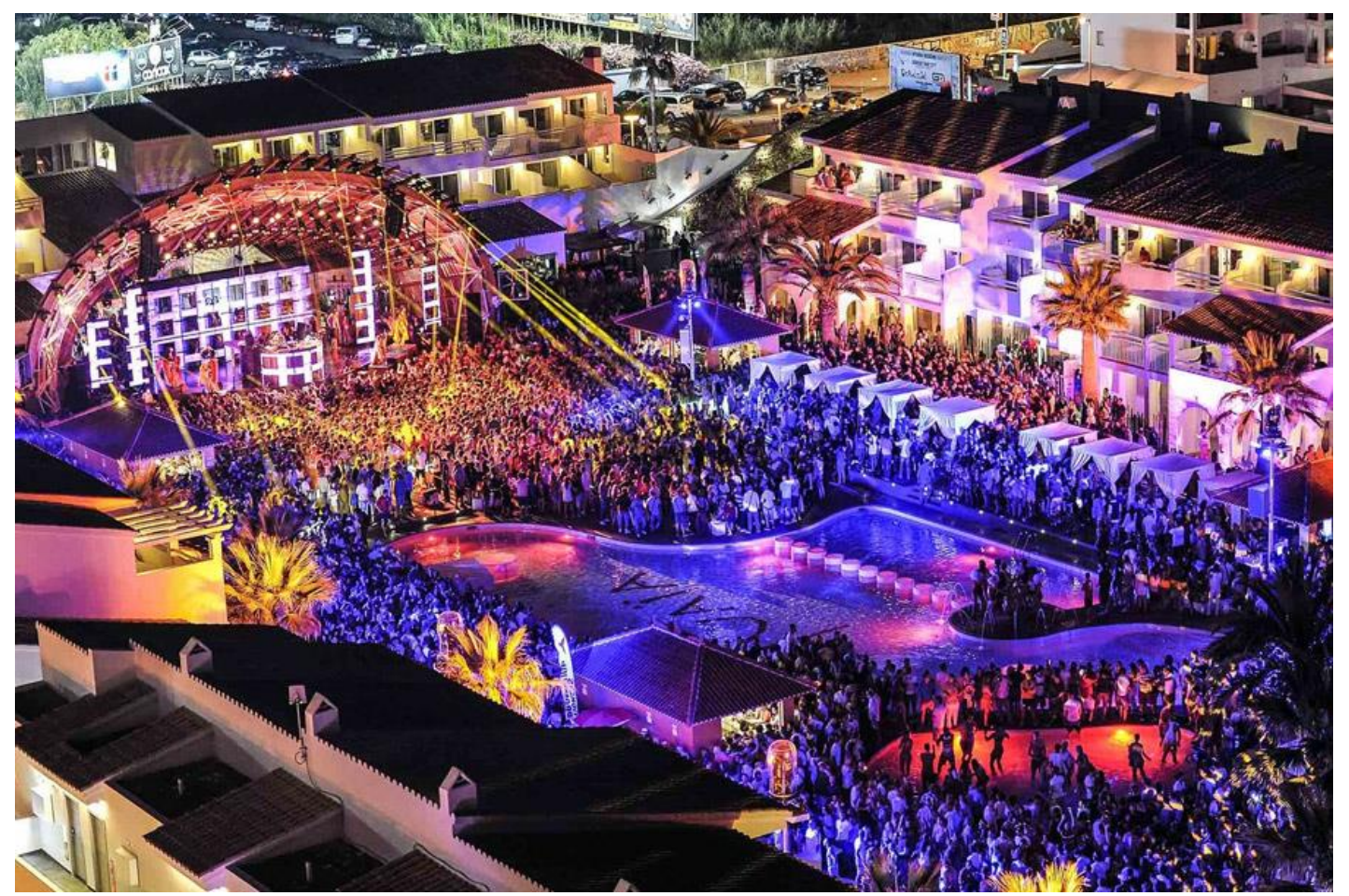

Figura 7: Ushuaïa Ibiza Beach Hotel, Playa d'en Bossa (PALLADIUM HOTEL GROUP).

2.2.4. Restaurant \& Cabaret: recientemente están abriendo restaurantes con espectáculo como es el caso de Lío, con un espectáculo inspirado en el cabaret, SubliMotion, que busca convertir las cenas en un espectáculo para la percepción y la emoción, o Heart, creado entre los hermanos Adrià y el Circo del Sol. El Restaurante Cabaret Lío (Figura 8) pertenece al grupo Pachá y es el resultado de la reconversión de la antigua discoteca El Divino.

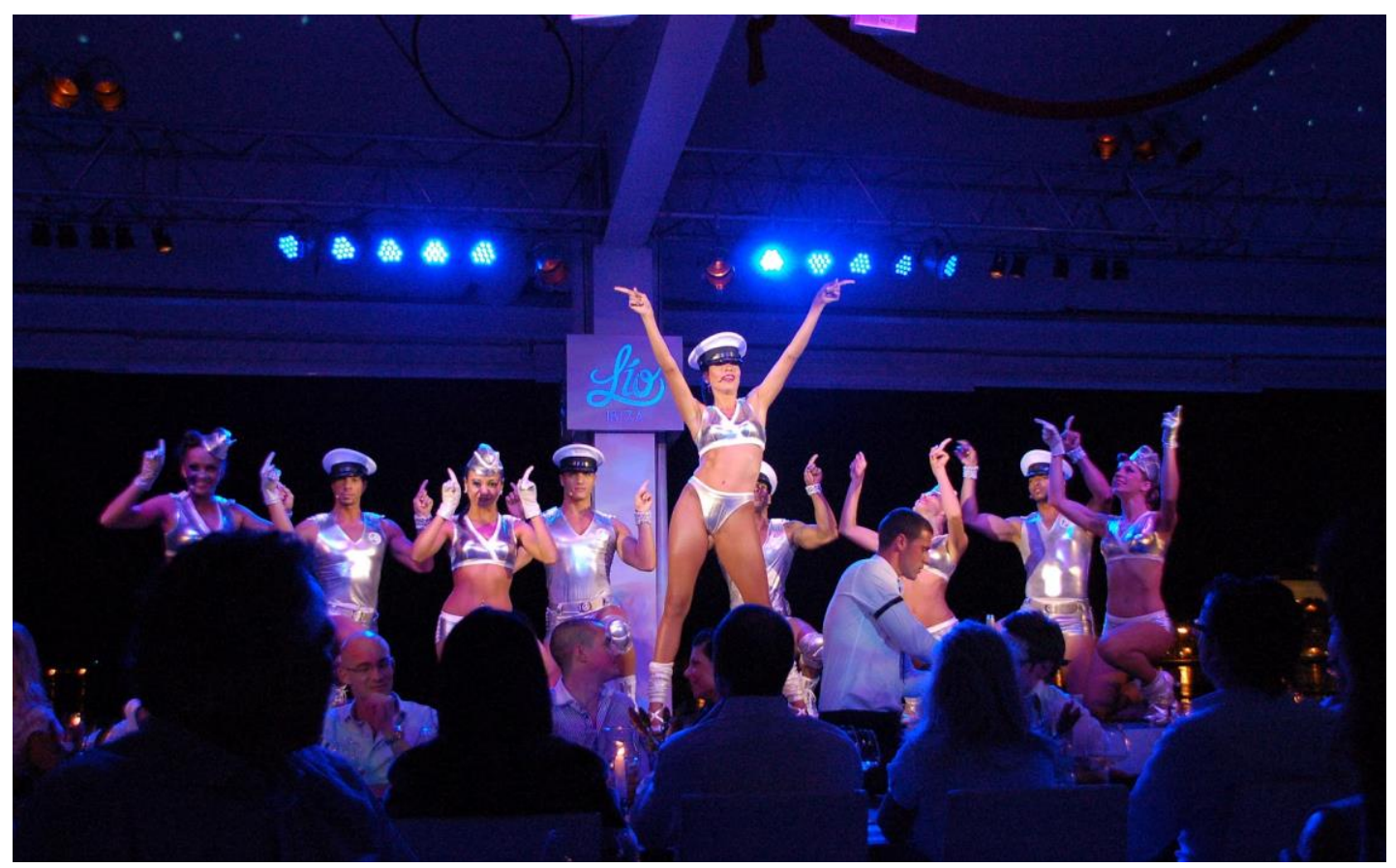

Figura 8: Espectáculo en el restaurante Cabaret Lío (RESTAURANTE CABARET Lío). 
2.2.5. Party Boat: los Party Boat son embarcaciones que organizan excursiones de unas horas por la costa de la isla y que han incorporado dj's y bar de copas al viaje (Figura 9), siendo en la actualidad muy polémicos y sujetos a inspecciones, por los riesgos que implica la celebración de fiestas en pequeñas embarcaciones durante la noche y por las molestias que causan en los residentes de las zonas costeras.

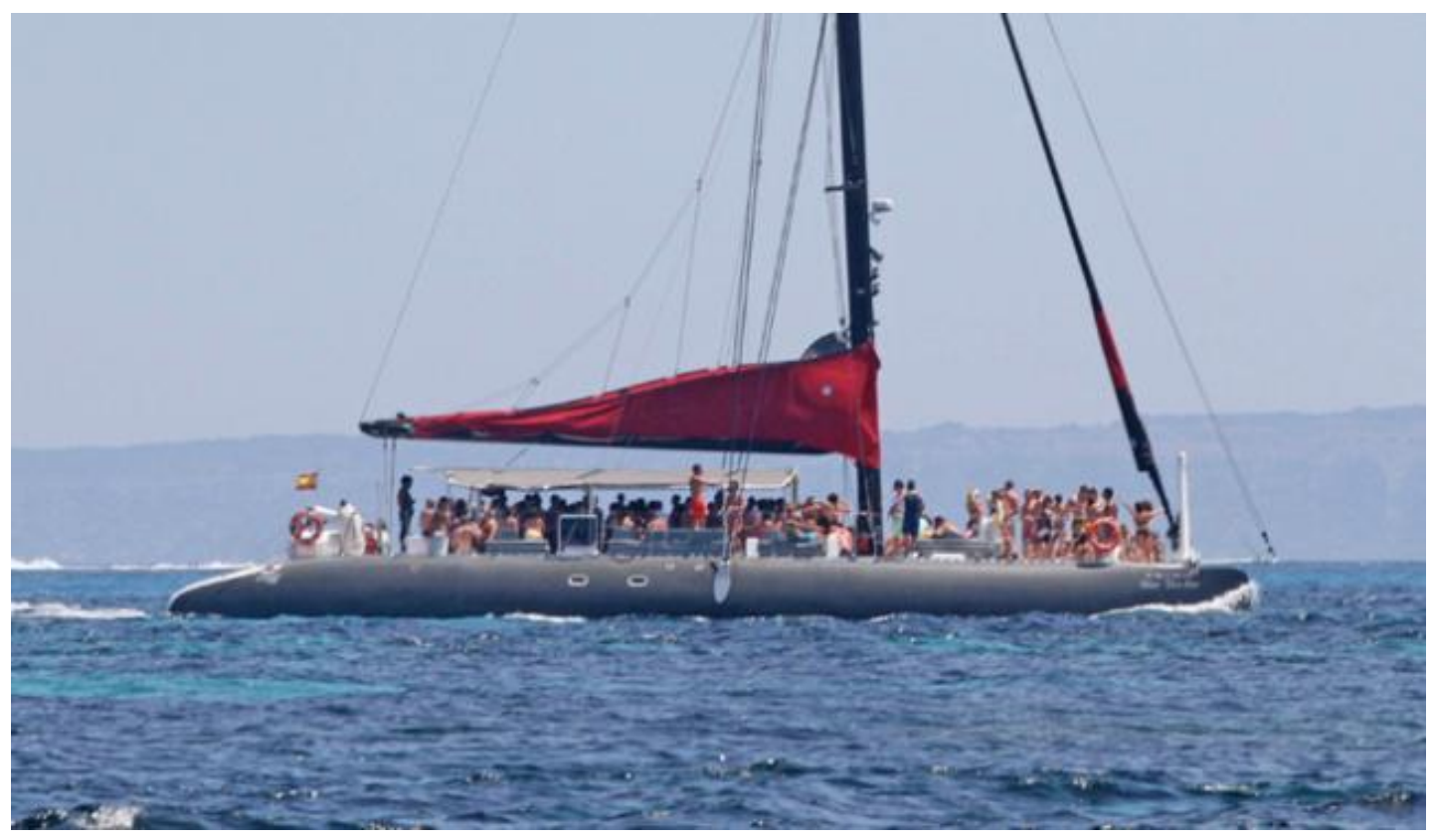

Figura 9: Party Boat (DIARIO DE IBIZA).

\section{CONCLUSIONES}

Ibiza es un referente mundial en el sector, como muestran las tablas 1 y 2 , principalmente en verano. La oferta de ocio nocturno no está formada sólo por discotecas, porque muchos otros tipos de establecimientos han incorporado dj's, música electrónica y otros elementos propios de las discotecas en su oferta nocturna. Ello lleva a proponer una primera división entre discotecas (Party) y el resto de oferta (Pre-Party): bares, pubs, hoteles, restaurantes, barcos, etc. Pero incluso dentro de las discotecas hay diferencias muy importantes en la oferta (Hard, Soft, Ambient, After Hours, etc.), el tamaño (Club y Super Club) y el prestigio internacional (Big Club, Global Club, etc.). Esta heterogeneidad en la oferta hace muy difícil cuantificar el sector, ya que los pocos datos disponibles son parciales.

La principal diferencia entre los dos grandes grupos es que las discotecas son establecimientos cuya actividad declarada principal es el ocio nocturno, cobrando entrada (mención aparte merecen las listas VIP), y el segundo grupo (Beach Club, Disco Pub, Hotel Club y Party Boat) son empresas cuya actividad principal no es el ocio nocturno sino la hostelería (cafeterías, restaurantes, hoteles, etc.) pero han adoptado elementos de las discotecas como oferta diferenciadora, cobrando entrada o no según el caso. Las diferencias entre ambos grupos llegan al nivel fiscal, ya que las discotecas tienen que aplicar un IVA del $21 \%$ mientras que el resto aplica el IVA turístico del 10\%, algo considerado competencia desleal por los empresarios de las discotecas. Esta acusación de competencia desleal ha llevado a que sean muy difíciles las acciones coordinadas dentro del sector, situación agravada por las desavenencias entre los principales empresarios de las discotecas. 


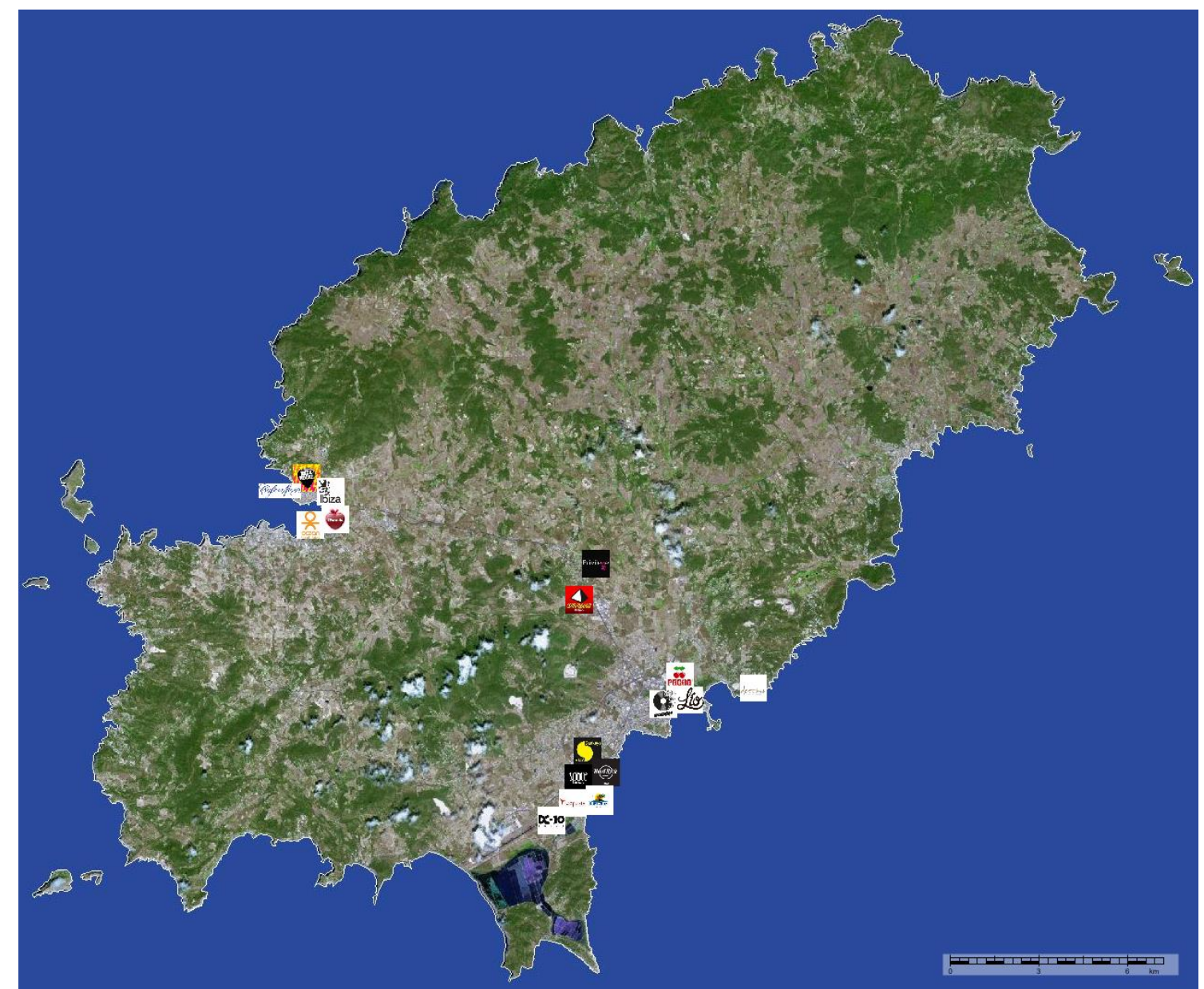

Figura 10: Principales establecimientos de relevancia internacional (GOOGLE MAPS y elaboración propia).

La importancia mundial de diversos establecimientos (Figura 10) y la frecuencia con que aparecen formulas innovadoras en Ibiza permite plantear que esta clasificación es posible usarla de referencia para clasificar establecimientos en otras regiones del mundo. Esta clasificación es repetible en otras zonas, tanto urbanas como de costa, tanto pequeñas como grandes. Aunque posiblemente, en otros destinos, no haya ejemplos de alguna de las categorías: en destinos de interior no habrá Beach Clubs o Party Boats; en zonas con una regulación estricta en cuanto a ruidos existirá poca oferta de Pre-Party y en zonas con un control férreo de los horarios no existirán After Hours; en algunas regiones no será posible la oferta de ambiente por diversos motivos; en los destinos con menor relevancia internacional no habrá Global Clubs, Big Clubs o Super Clubs en general; etc. Las limitaciones de esta clasificación son esencialmente de dos tipos:

- Como toda clasificación, esta depende de las variables tomadas para ello. En este caso se ha adoptado una visión de marketing ya que variables como el tipo de actividad en la que está dado de alta, el tamaño del establecimiento, la relevancia y otras características de la oferta son muy relevantes para el gestor de la oferta y para el potencial cliente.

- La clasificación se ha realizado en base a la realidad existente en la isla en 2015. Muchos tipos de oferta tienen menos de diez años de antigüedad y es posible que sigan apareciendo nuevos tipos de oferta, en especial en la categoría Pre-Party. Por tanto es probable que en el futuro sea necesario ampliar esta categoría. 
Dada la aún escasa literatura existente sobre la gestión de la oferta de ocio nocturno, las futuras líneas de investigación consistirán en profundizar, mediante diversas metodologías (análisis descriptivos, causales, etc.), en el conocimiento de la oferta y demanda de lbiza y otros destinos turísticos.

\section{REFERENCIAS BIBLIOGRÁFICAS}

1. AGÈNCIA DE TURISME DE LES ILLES BALEARS. El turismo a les Illes Balears. Anuari 2014. Palma de Mallorca: Agència de Turisme de les Illes Balears, 2015.

2. AGUIRRE, B.E. et al. Normative collective behavior in the station building fire. Social Science Quarterly, v. 92, n. 1, p. 100-118, 2011.

3. ALLEMAND, R. De la mystification des pratiques à la négation du réel? Ethnographie de discothèques montpelliéraines. Deviance et Societe, v. 34, n. 1, p. 29-48, 2010.

4. ANDERSON, T., DALY, K., RAPP, L. Clubbing masculinities and crime: A qualitative study of Philadelphia nightclub scenes. Feminist Criminology, v. 4, n. 4, p. 302-332, 2009.

5. ANDERSSON, J. Vauxhall's post-industrial pleasure gardens: 'Death wish' and hedonism in 21stcentury London. Urban Studies, v. 48, n. 1, p. 85-100, 2011.

6. BEACH, E.F., WILLIAMS, W., GILLIVER, M. Hearing protection for clubbers is music to their ears. Health Promotion Journal of Australia, v. 21, n. 3, p. 215-221, 2011.

7. BELLIS, M.A. et al. Relative Contributions of Holiday Location and Nationality to Changes in Recreational Drug Taking Behaviour: A Natural Experiment in the Balearic Islands. European Addiction Research, v. 15, n. 2, p. 78-86, 2009.

8. BELLIS, M.A. et al. The role of an international nightlife resort in the proliferation of recreational drugs. Addiction, v. 98, n. 12, p. 1713-1721, 2003.

9. BELLIS, M.A., HUGHES, K. Sexual behaviour of young people in international tourist resorts. Sexually Transmitted Infections, v. 80, n. 1, p. 43-47, 2004.

10. BORA BORA. Disponível em: <http://www.boraboraibiza.net/> Accesso em: 12 abr. 2015.

11. BOYD, J. Producing Vancouver's (hetero)normative nightscape. Gender, Place and Culture, v. 17, n. 2, p. 169-189, 2010.

12. BROWN, D., ROSEMAN, M.G., HAM, S. Perceptions of a Bible Belt State's proposed casino gaming legislation bi religious affiliation: the case of Kentucky residents. UNLV Gaming Research \& Review Journal, v. 7, n. 1, p. 49-58, 2003.

13. CAFÉ DEL MAR. Disponível em: <http://www.cafedelmarmusic.com/> Accesso em: 10 abr. 2015.

14. CALAFAT, A. et al. Nightlife young risk behaviours in Mediterranean versus other European cities: Are stereotypes true? European Journal of Public Health, v. 21, n. 3, p. 311-315, 2011.

15. CAMPO, D., RYAN, B.D. The entertainment zone: Unplanned nightlife and the revitalization of the American downtown. Journal of Urban Design, v. 13, n. 3, p. 291-315, 2008.

16. COULTER, R.L., HERMANS, C.M., PARKER, R.S. Religiosity and generational effects on gambling: Support for and opposition to introducing casino gambling in a non-gambling tourist entertainment environment. Journal of Business Research, v. 66, n. 9, p. 1682-1688, 2013. 
17. DAMANI, R. et al. Emotional intimacy predicts condom use: Findings in a group at high sexually transmitted disease risk. International Journal of STD and AIDS, v. 20, n. 11, p. 761-764, 2009.

18. DARGAN, P.I., ALBERT, S., WOOD, D.M. Mephedrone use and associated adverse effects in school and college/university students before the UK legislation change. QJM, v. 103, n. 11, p. 875-879, 2010.

19. DEAN, R., MULLIGAN, J. First aid provision in nightclubs and other entertainment venues. Nursing standard, v. 24, n. 9, p. 35-40, 2009.

20. DIARIO DE IBIZA. Disponível em: <http://www.diariodeibiza.es/> Accesso em: 15 abr. 2015.

21. DISCOTECA PRIVILEGE. Disponível em: <http://privilegeibiza.com/> Accesso em: 10 abr. 2015.

22. DJMAG. Disponível em: <http://www.top100clubs.com/> Accesso em: 15 abr. 2015.

23. DOWNING, J. et al. Factors associated with risky sexual behaviour: A comparison of British, Spanish and German holidaymakers to the Balearics. European Journal of Public Health, v. 21, n. 3, p. 275-281, 2011.

24. ELLEDGE, R.O.C. et al. The role of alcohol in maxillofacial trauma-a comparative retrospective audit between the two centers. Alcohol, v. 45, n. 3, p. 239-243, 2011.

25. FORSYTH, A.J.M. Front, side, and back-loading: Patrons' rationales for consuming alcohol purchased off-premises before, during, or after attending nightclubs. Journal of Substance Use, v. 15, n. 1, p. 31-41, 2010.

26. FORSYTH, A.J.M., LENNOX, J.C. Gender differences in the choreography of alcohol-related violence: An observational study of aggression within licensed premises. Journal of Substance Use, v. 15, n. 2, p. 75-88, 2010.

27. GOOGLE MAPS. Disponível em: <https://www.google.es/maps> Accesso em: 18 abr. 2015.

28. GRUPO PACHÁ. Disponível em: <http://www.pacha.com/> Accesso em: 10 abr. 2015.

29. GUÉGUEN, N. Menstrual cycle phases and female receptivity to a courtship solicitation: an evaluation in a nightclub. Evolution and Human Behavior, v. 30, n. 5, p. 351-355, 2009.

30. GUIDA IBIZA. Disponível em: <http://www.guida-ibiza.com/> Accesso em: 12 abr. 2015.

31. HALIOS, C. et al. Exposure to fine particulate matter in ten night clubs in Athens Greece: Studying the effect of ventilation, cigarette smoking and resuspension. Science of the Total Environment, v. 407, n. 17, p. 4894-4901, 2009.

32. HENDRIE, C.A., MANNION, H.D., GODFREY, G.K. Evidence to suggest that nightclubs function as human sexual display grounds. Behaviour, v. 146, n. 10, p. 1331-1348, 2009.

33. HONG, L.K., DUFF, R.W. The center and the peripheral - Functions and locations of dance clubs in Los Angeles. Journal of Contemporary Ethnography, v. 26, n. 2, p. 182-201, 1997.

34. HUANG, J. Night on the town. Taiwan Review, v. 61, n. 6, p. 18-21, 2011.

35. HUGHES, K. et al. Alcohol, drugs, sex and violence: health risks and consequences in young British holidaymakers to the Balearics. Adicciones, v. 21, n. 4, p. 265-277, 2009.

36. HUGHES, K. et al. Predictors of violence in young tourists: a comparative study of British, German and Spanish holidaymakers. European Journal of Public Health, v. 18, n. 6, p. 569574, 2008. 
37. HUGHES, K., BELLIS, M.A. Sexual behaviour among casual workers in an international nightlife resort: a case control study. BMC Public Health, v. 6, p. 39, 2006.

38. INSTITUT D'ESTAdíSTICA DE LES ILLES BALEARS (IBESTAT) (2015). Estadísticas. Palma de Mallorca: Ibestat. Disponível em: <http://ibestat.caib.es//> Accesso em: 15 fev. 2015.

39. JANES, P., COLLISON, J. Community leader perceptions of the social and economic impacts of Indian gaming. UNLV Gaming Research \& Review Journal, v. 8, n. 1, p. 13-30, 2004.

40. JÄRVINEN, M., RAVN, S. From recreational to regular drug use: Qualitative interviews with young clubbers. Sociology of Health and Illness, v. 33, n. 4, p. 554-569, 2011.

41. JONES, L. et al. Reducing harm in drinking environments: A systematic review of effective approaches. Health and Place, v. 17, n. 2, p. 508-518, 2011.

42. KO, D.W., STEWART, W.P. A structural equation model of residents' attitudes for tourism development. Tourism Management, v. 23, n. 5, p. 521-530, 2002.

43. KUBACKI, K. et al. Comparing nightclub customers' preferences in existing and emerging markets. International Journal of Hospitality Management, v. 26, n. 4, p. 957-973, 2007.

44. LEE, C.K., BACK, K.J. Examining structural relationships among perceived impact, benefit, and support for casino development based on 4 year longitudinal data. Tourism Management, v. 27, n. 3, p. 466-480, 2006.

45. LEE, C.K., BACK, K.J. Pre- and post-casino impact of residents' perception. Annals of Tourism Research, v. 30, n. 4, p. 868-885, 2003.

46. LEE, C.K., KANG, S., REISINGER, Y. Community attachment in two rural gaming communities: Comparisons between Colorado gaming communities, USA and Gangwon gaming communities, South Korea. Tourism Geographies, v. 12, n. 1, p. 140-168, 2010.

47. LEE, C.K., KIM, S.S., KANG, S. Perceptions of casino impacts: A Korean longitudinal study. Tourism Management, v. 24, n. 1, p. 45-55, 2003.

48. LOCKYER, T. Perceptions of the Hamilton New Zealand casino upon local residents. Tourism Review, v. 67, n. 4, p. 12-25, 2012.

49. MAK, Y.T. et al. The toxic effect of ketamine on SH-SY5Y neuroblastoma cell line and human neuron. Microscopy Research and Technique, v. 73, n. 3, p. 195-201, 2010.

50. MEASHAM, F., HADFIELD, P. Todo empieza con «E»: Exclusión, etnicidad y formación de élites en el mundo actual de las discotecas inglesas. Adicciones, v. 21, n. 4, p. 363-386, 2009.

51. MOSS, G.A., PARFITT, S., SKINNER, H. Men and women: Do they value the same things in mainstream nightclubs and bars. Tourism and Hospitality Research, v. 9, n. 1, p. 61-79, 2009.

52. NICHOLS, M., GIACOPASSI, D., STITT, B.G. Casino gambling as a catalyst of economic development: Perceptions of residents in new casino jurisdictions. Tourism Economics, v. 8, n. 1, p. 59-76, 2002.

53. PALLADIUM HOTEL GROUP. Disponível em: <http://www.palladiumhotelgroup.com/> Accesso em: 15 abr. 2015.

54. POTIER, M. et al. The risks of amplified music for disc-jockeys working in nightclubs. Ear and Hearing, v. 30, n. 2, p. 291-293, 2009.

55. RAMÓN, E. Historia del turismo en Ibiza y Formentera. 1900-2000. Eivissa: Genial Ediciones 
Culturals, 2001.

56. RAMÓN, J., ÁLVAREZ, D. Actitud de los residentes hacia el ocio nocturno: El caso de Punta del Este (Uruguay). International Journal of Scientific Management and Tourism, v. 2, n. 1, p. 207-228, 2016.

57. RAMÓN, J., AZPELICUETA, M.C., SERRA, A. Ibiza Nightlife: Descripción de un referente mundial en su sector. REDMARKA: Revista Digital de Marketing Aplicado, v. 15, n. 1, p. 101-139, 2015.

58. RAMÓN, J., SERRA, A. Historia del turismo en Ibiza: Aplicación del Ciclo de Vida del destino Turístico en un destino maduro del Mediterráneo. PASOS: Revista de Turismo y Patrimonio Cultural, v. 12, n. 4, p. 899-913, 2014.

59. RESTAURANTE CABARET Lío. Disponível em: <http://www.lioibiza.com/> Accesso em: 15 abr. 2015.

60. RIDNER, S.L. et al. College students' exposure to tobacco marketing in nightclubs and bars. Journal of American College Health, v. 59, n. 3, p. 159-164, 2011.

61. ROWE, S.C. et al. Establishments licensed to serve alcohol and their contribution to policerecorded crime in Australia: Further opportunities for harm reduction. Journal of Studies on Alcohol and Drugs, v. 71, n. 6, p. 909-916, 2010.

62. SERRA, A., RAMÓN, J. Host community resignation to nightclub tourism. Current Issues in Tourism, 2016 DOI:10.1080/13683500.2016.1161604

63. SKINNER, H. et al. Polish nightclubs and bars: Management insights into what customers really want. Journal for East European Management Studies, v. 13, n. 2, p. 154-169, 2008.

64. SKINNER, H., MOSS, G., PARFITT, S. Nightclubs and bars: What do customers really want? International Journal of Contemporary Hospitality Management, v. 17, n. 2, p. 114-124, 2005.

65. STANTON, C.R. et al. Promoting tobacco through the international language of dance music: British American tobacco and the Ministry of Sound. European Journal of Public Health, v. 21, n. 1, p. 21-28, 2011.

66. STITT, B.G., GIACOPASSI, D., NICHOLS, M. Gambling among older adults: A comparative analysis. Experimental Aging Research, v. 29, n. 2, p. 189-203, 2003.

67. SUMNALL, H. et al. A choice between fun or health Relationships between nightlife substance use, happiness, and mental well-being. Journal of Substance Use, v. 15, n. 2, p. 89-104, 2010.

68. SUTTON, R., GRIFFITHS, M.D. The casino attitudes scale: The development of a new brief psychometric instrument. International Journal of Mental Health and Addiction, v. 6, n. 2, p. 244-248, 2008.

69. TODOROVIC, M., BAKIR, A. Inaudible noise: Belgrade's Academy Club: Legacy, old locals and new spaces. Leisure Studies, v. 24, n. 4, p. 415-434, 2005.

70. VONG, F. Changes in residents' gambling attitudes and perceived impacts at the fifth anniversary of Macao's gaming deregulation. Journal of Travel Research, v. 47, n. 3, p. 388397, 2009.

71. VONG, F. Gambling attitudes and gambling behavior of residents of Macao: The Monte Carlo of the Orient. Journal of Travel Research, v. 42, n. 3, p. 271-278, 2004.

72. VONG, F., MCCARTNEY, G. Mapping resident perceptions of gaming impact. Journal of Travel 
Research, v. 44, n. 2, p. 177-187, 2005.

73. WINTER MUSIC CONFERENCE. Disponível em: <http://www.wintermusicconference.com/> Accesso em: 15 abr. 2015. 